\title{
Interdecadal variations in persistent anomalous cold events over Asian mid-latitudes
}

\author{
Ning Shi ${ }^{1}\left[\right.$ C Xiaoqiong Wang $^{2} \cdot$ Pingyu $^{2}$ Tian $^{2}$
}

Received: 21 February 2018 / Accepted: 4 July 2018 / Published online: 18 July 2018

(c) The Author(s) 2018

\begin{abstract}
Based on the Japanese 55-year reanalysis daily data, this study finds that the frequency of persistent cold events from Lake Balkhash to Lake Baikal exhibits a clear interdecadal variation. Circulation characteristics, such as interdecadal variations in regional persistent cold event frequencies, are the focus of this study. During the 57-year period, a subperiod from the mid-1980s to the late 1990s exhibits inactive characteristics compared with those before and after during the study period. On a subseasonal timescale, the typical circulation patterns of persistent cold events are characterized by wave-train anomalies across the Atlantic Ocean and Eurasian continent, with significantly positive height anomalies that persist over the Ural Mountains in the upper troposphere, positive SLP anomalies over Eurasian mid- to high latitudes and cold SAT anomalies from Lake Balkhash to Lake Baikal. The changes in background circulation at the interdecadal timescale correspond well with the typical circulation patterns at the subseasonal timescale, indicating their important role in modulating the frequency of persistent cold events. Interdecadal changes in the background circulation can be partially explained by transient eddy feedback forcing.
\end{abstract}

Keywords Interdecadal variation $\cdot$ Persistent anomalous cold events

\section{Introduction}

The global climate experiences remarkable changes, which have been primarily characterized by global warming during the last 100-year period. Currently, the Earth is entering a global warming hiatus period because globally averaged surface air temperatures (SATs) have not exhibited a significant warming trend since 1998 (IPCC 2013). Many studies have consistently concluded that global warming affects the frequency, intensity, and duration of extreme events, and several of these changes are projected to continue in the future (IPCC 2013; Chen and Sun 2015).

Ning Shi

shining0826@hotmail.com

1 Collaborative Innovation Center on Forecast and Evaluation of Meteorological Disasters, Key Laboratory of Meteorological Disaster of Ministry of Education, Nanjing University of Information Science and Technology, Nanjing, China

2 College of Atmospheric Science, Nanjing University of Information Science and Technology, Nanjing 210044, China
Although the global mean SAT has clearly increased overall, the spatial heterogeneity of global warming plays an important role in the resulting climate impacts. Particularly, the near-surface warming of the Northern Hemisphere high latitudes is twice that of lower latitudes (Serreze et al. 2009; Screen and Simmonds 2010) and has become the most remarkable warming feature. This observed phenomenon is termed as the polar or Arctic amplification, which occurs in all seasons but is strongest in autumn and winter.

Another interesting phenomenon is the anomalously cold conditions that have occurred during the past few winters in the mid-latitude region of the Northern Hemisphere. For example, a 50-year persistent and extreme low temperature event affected southern China from mid-January 2008 to early February 2008 (Tao and Wei 2008). An anomalous heavy snowfall event wreaked havoc in large parts of the United States and northwestern Europe during the winters of 2009-2010 and 2010-2011, and extremely icy and snowy conditions persisted over the eastern half of the United States in the winter of 2013-2014 (Palmer 2014; Wallace et al. 2014). The frequent occurrence of cold weather events under a warming background seems counterintuitive. Because Arctic amplification is related 
to Arctic sea ice loss (Serreze et al. 2009; Screen and Simmonds 2010; Screen et al. 2012), several studies have stated that Arctic amplification and/or Arctic sea ice loss have contributed to anomalously cold conditions over the Northern Hemisphere during the past few winters (Francis and Vavrus 2012; Liu et al. 2012a, b; Mori et al. 2014; Han et al. 2016). Specifically, Arctic amplification and/ or Arctic sea ice loss could amplify the wave amplitude and decrease its phase speed (Francis and Vavrus 2012), which would induce more frequent blocking occurrences over mid-latitudes (Liu et al. 2012a, b; Mori et al. 2014). Although these explanations have been questioned by other observational studies (Barnes 2013; Screen and Simmonds 2013; Palmer 2014), cooling tendencies have occurred over the United States and Eurasian mid-latitudes from 1990 to 2013 (Cohen et al. 2014).

Compared with the average climate, extreme climate events are more closely related to meteorological disasters and have more direct impacts on society. Persistent cold weather is a type of extreme climate event that has produced substantial societal concern in China, especially during the last decade (Wen et al. 2009; Zhou et al. 2009; Peng and Bueh 2011; Bueh et al. 2011a, b). Based on daily station data, Peng and Bueh (2011) identified 52 extensive and persistent extreme cold events in China from 1951 to 2009. They implicitly showed a decrease in extreme event frequencies over China after the mid-1980s, which is consistent with the interdecadal variations in East Asian winter monsoons (Nakamura et al. 2002; Jhun and Lee 2004; Wang and Fan 2013; Wang and Chen 2014). Cohen et al. (2014) showed that the number of days continuously below freezing has increased and that minimum temperatures have decreased since 1990, which implies an increase in cold days during the last decade. During this time, the loss of Arctic sea ice may have increased the persistence of the Ural blocking high (Liu et al. 2012a, b; Mori et al. 2014), which causes an increase in persistent cold weather over Asia. Thus, fundamental changes in atmospheric circulations have occurred during recent decades. This study will explore the long-term variations in persistent cold events (PCEs) over mid- to high latitude regions in Asia to discuss the underlying circulation characteristics.

This study mainly focuses on the following problems: (1) whether PCEs show interdecadal variations over the mid- and high-latitude regions in Asia. (2) What the typical circulation characteristics, as represented by the geopotential height, sea level pressure and SAT anomalies, are for PCEs, and (3) whether the background circulation can modulate PCE frequencies. The rest of the paper is organized as follows: we introduce the reanalysis datasets and methods used in this study in Sect. 2. The statistical results based on the reanalysis data are presented in Sect. 3. Section 4 provides a summary and discussion.

\section{Data and methods}

\subsection{Data}

In this study, we used daily data from the Japanese 55-year reanalysis (JRA-55) project conducted by the Japan Meteorological Agency from 1958 to 2015 (Kobayashi et al. 2015). The dataset was available on a standard global longitude/latitude grid with intervals of $1.25^{\circ}$. The meteorological variables used are geopotential height, wind velocity and air temperature, all of which were measured on 37 isobaric surfaces from 1000 to $1 \mathrm{hPa}$. The sea level pressure (SLP) is used to evaluate the variation in the Siberian High. To identify the PCEs, the SAT at $2 \mathrm{~m}$ was also utilized.

\subsection{Methods}

\subsubsection{Processing of the data}

The present study focuses on PCEs, which have a low-frequency nature and may be interrupted by high-frequency weather systems. To minimize the influence of high-frequency weather systems, all raw data were low-pass filtered by removing 8-day high-pass-filtered disturbances to isolate the slowly varying component. Notably, there is no qualitative change in the final results if the unfiltered data sets are used except for a slight reduction in the frequency of the PCEs (not shown). Due to data loss at the beginning and end of a data sequence when applying the Lanczos filtering procedure (Duchon 1979), we extended the winter period from mid-November in the initial year to mid-March of the following year. Our analysis was limited to 57 winters (i.e., December to February) from $1958 / 1959$ to $2014 / 2015$, which was simplified to 1959-2015. The final results did not change qualitatively when NCEP/ NCAR reanalysis data were utilized during the same period; this analysis is discussed in the last section.

The linear trend of SATs (DJF season) at each grid point for the 57 years is computed using the linear least squares fitting method. The Mann-Kendall non-parametric test is used to calculate the statistical significances of the trends. Figure 1 shows that the warming trend is distinct over most areas of Asia, except for India and northwestern China, with the greatest warming trend occurring over northwestern China. To focus on interdecadal variations, this study removes the long-term linear trend from the daily SAT data and other meteorological variables for the sake of consistency.

\subsubsection{Identification of PCEs}

The local anomaly of a given variable on a particular day was defined as its departure from the local value of the climatological mean annual cycle for the corresponding 


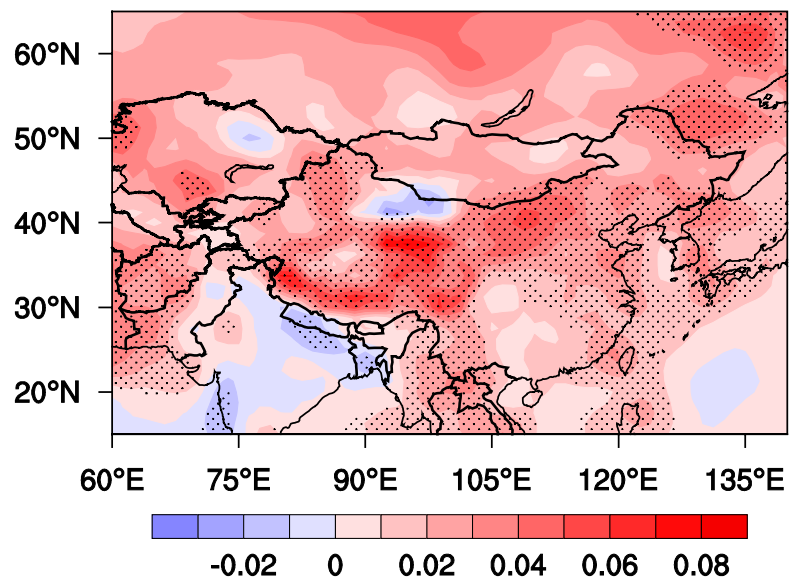

Fig. 1 Linear trends of wintertime (December to February) surface air temperature evaluated at every grid point from 1958 to 2015 (units: ${ }^{\circ} \mathrm{C} /$ year). The stippling indicates significant trends at the 0.05 confidence level according to the Mann-Kendall non-parametric test

calendar date. The climatological mean annual cycle was defined as the 31-day running mean of the 57-year climatological mean daily fields. In other words, the climatology mean annual cycle for every particular calendar day is obtained by averaging the 31-day sequence of the daily climatology mean centred on the particular calendar day. The anomalous SATs at every particular calendar day were further normalized locally by using the standard deviation of anomalous SATs over 31 days/year $\times 57$ years $=1767$ days, where the annual 31-day sequence is centred on that particular calendar day. Clearly, this method also takes into account the annual cycle of the local daily standard deviation. The normalized SAT anomalies were used for detecting PCEs.

For each grid point, PCEs are identified if (1) the local normalized SAT anomalies are less than -0.8 standard deviations (STD) and (2) persist for longer than or equal to 8 days. Other threshold values are tested (for example, 1.0 and 10 days for the amplitude and duration, respectively), and the final results are not qualitatively different. Based on the gridded PCEs, it is easy to determine the preferential regions and long-term variations in PCEs.

\subsubsection{Transient eddy feedback forcing}

The quasi-geostrophic potential vorticity (PV) equation (Eq. (1)) shows that migratory transient eddies can exert barotropic and baroclinic influences on low-frequency circulations over mid- to high latitudes through the convergence of vorticity flux $\left(D^{V O R T}\right)$ and heat flux $\left(D^{H E A T}\right)$, respectively (Lau and Holopainen 1984):

$$
\left\{\frac{1}{f} \nabla^{2}+f \frac{\partial}{\partial p}\left(\frac{1}{\sigma} \frac{\partial}{\partial p}\right)\right\} \frac{\partial \Phi}{\partial t}=\underbrace{-\nabla \cdot \overline{V^{\prime} \varsigma^{\prime}}}_{D^{\text {VORT }}}+\underbrace{f \frac{\partial}{\partial p}\left(\frac{\nabla \cdot \overline{V^{\prime} \theta^{\prime}}}{\bar{S}}\right)}_{D^{\text {HEAT }}}+R
$$

where $\Phi$ is the geopotential, $\boldsymbol{V}$ is the horizontal velocity, $f$ is the Coriolis parameter, $\varsigma$ is the relative vorticity, $\theta$ is the potential temperature, $\sigma=-(\alpha / \theta)(\partial \theta / \partial p)$ is the static stability parameter (assumed to be a function of pressure $p$ only), $\alpha$ is the specific volume, and $\bar{S}$ is the hemispheric mean of $-\partial \bar{\theta} / \partial p$. Here, the overbar and the prime represent the components with frequencies lower than and higher than 8 days, respectively. The term $R_{1}$ in Eq. (1) represents all remaining components in the quasi-geostrophic potential vorticity balance, such as horizontal advection by the low-frequency flow, diabatic effects and friction.

The boundary conditions are

$$
\begin{aligned}
\frac{\partial}{\partial p}\left(\frac{\partial \Phi}{\partial t}\right)^{V O R T} & =0 \\
\frac{\partial}{\partial p}\left(\frac{\partial \Phi}{\partial t}\right)^{H E A T} & =\frac{R}{p} \nabla \cdot \overline{T^{\prime} V^{\prime}}
\end{aligned}
$$

at $p=100$ and $1000 \mathrm{hPa}$.

Equation (1) is solved by using the spherical harmonics with the T21 truncation, which has been documented in detail in Holopainen and Fortelius (1987) and Takaya and Nakamura (2005).

\subsubsection{Wave activity flux}

Stationary Rossby wave propagation associated with regional PCEs is analysed by applying the wave-activity flux formulated by Takaya and Nakamura (2001). The flux is expressed as

$W=\frac{p}{2000|\boldsymbol{U}|}\left(\begin{array}{c}U\left(v^{\prime 2}-\psi^{\prime} v_{x}^{\prime}\right)+V\left(-u^{\prime} v^{\prime}+\psi^{\prime} u_{x}^{\prime}\right) \\ U\left(-u^{\prime} v^{\prime}+\psi^{\prime} u_{x}^{\prime}\right)+V\left(u^{\prime 2}+\psi^{\prime} u_{y}^{\prime}\right) \\ \frac{f_{0} R_{\mathrm{a}}}{N^{2} H_{0}}\left\{U\left(v^{\prime} T^{\prime}-\psi^{\prime} T_{x}^{\prime}\right)+V\left(-u^{\prime} T^{\prime}-\psi^{\prime} T_{y}^{\prime}\right)\right\}\end{array}\right)$

where the prime denotes the quasi-geostrophic perturbations (derived from the composites of the daily 8-day low-passfiltered anomalies associated with PCEs events), $\psi^{\prime}$ is the perturbation geostrophic stream function, $V^{\prime}=\left(u^{\prime}, v^{\prime}\right)$ is the perturbation geostrophic wind velocities, $\boldsymbol{U}=(u, v)$ is the horizontal basic flow velocity, and the other notations in Eq. (2) are standard. In theory, the flux $W$ is independent of the wave phase and is parallel to the local group velocity of a stationary Rossby wave train. In our evaluation, the climatological mean annual cycle, which has been described in Sect. 2.2.2, was taken as the horizontal basic flow $\boldsymbol{U}$. 


\section{Results}

\subsection{Frequency distribution}

Figure 2 shows the grid-based PCE frequency anomalies over Asia, which are evaluated by subtracting the 57 -year mean value from the local grid-based PCE frequency. If the threshold value of the amplitude is set to -0.8 STD (the second row in Fig. 2), the grid-based PCEs over midlatitudes $\left(40^{\circ} \mathrm{N}-60^{\circ} \mathrm{N}\right)$ occurred frequently from the late 1950s until the mid-1980s and became active again in the early 2000s after experiencing an inactive period (mid1980 s to the late 1990 s). Note that the situation is different at $35^{\circ} \mathrm{N}$. The grid-based PCEs that occurred over the Tibetan Plateau (between $75^{\circ} \mathrm{E}$ and $105^{\circ} \mathrm{E}$ ) exhibited a distinct interdecadal variation during an active period (mid-1980s to mid-2000s), while the grid-based PCEs at other longitudes showed a similar interdecadal variation to those at other mid-latitudes. Therefore, the frequency of PCEs over the Tibetan Plateau shows different decadal variations than those over the other mid-latitude regions of Asia. The latter is the focus of the present study. Different threshold values, such as -0.5 STD or -1.0 STD (the first and third rows of Fig. 1), did not change the above results qualitatively. Figure 2 shows that the 57 -year period is divided into three periods: 1959-1984, 1985-1999 and
2000-2014. For convenience, these three periods are referred to as the active period, the inactive period and the reactive period, respectively.

To further analyse the spatial distributions, the differences in grid-based PCE frequencies between these three periods are shown in Fig. 3. The inactive period is regarded as the reference period hereafter. Figure $3 \mathrm{a}$, b show the differences between the active period and the inactive period and between the reactive period and the inactive period, respectively. In comparison with the inactive period, the grid-based PCEs during the two active periods show a consistent and significant increase from Lake Balkhash to Lake Baikal (the BB region for simplicity). In addition, both northeastern China and the Huang-Huai River valley in China show the same sign changes. In contrast, the Tibetan Plateau has an opposite sign, which is consistent with the first column in Fig. 2. Due to the relatively large spatial scale, PCEs over the $\mathrm{BB}$ region are the focus of this study. The SAT is further area-averaged over the $\mathrm{BB}$ region $\left(\left[38.75^{\circ} \mathrm{N}-57.5^{\circ} \mathrm{N}\right.\right.$, $\left.75^{\circ} \mathrm{E}-105^{\circ} \mathrm{E}\right]$; the black rectangle in Fig. $3 \mathrm{a}, \mathrm{b}$ ), and all the regional PCEs, which are based on the standardized areaaveraged SAT anomalies, over this region are detected accordingly. Statistically, 45 regional PCEs over the BB region are identified during the 57 winters, with a mean frequency of 0.8 per winter, indicating their high occurrence frequency. The mean duration of these 45 regional events is 12 days. Clearly, the 11-year running mean frequency of

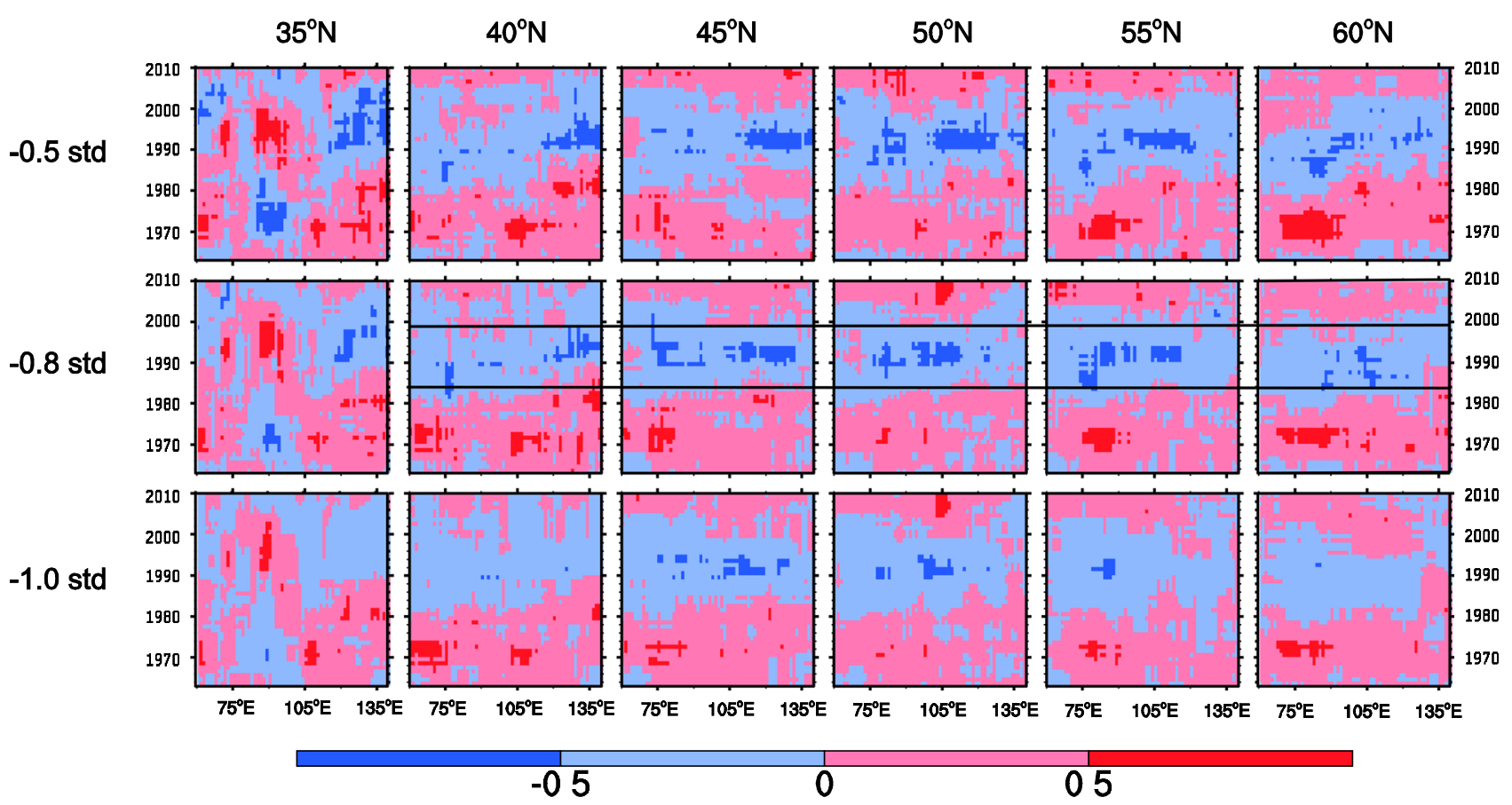

Fig. 2 Frequency anomalies of persistent cold events (PCEs) relative to the 57-year mean average. Thick black lines approximately indicate the boundaries that separate the periods with relatively high- and low-frequency PCEs. The columns from left to right indicate the frequency anomalies at different latitudes over Asia 

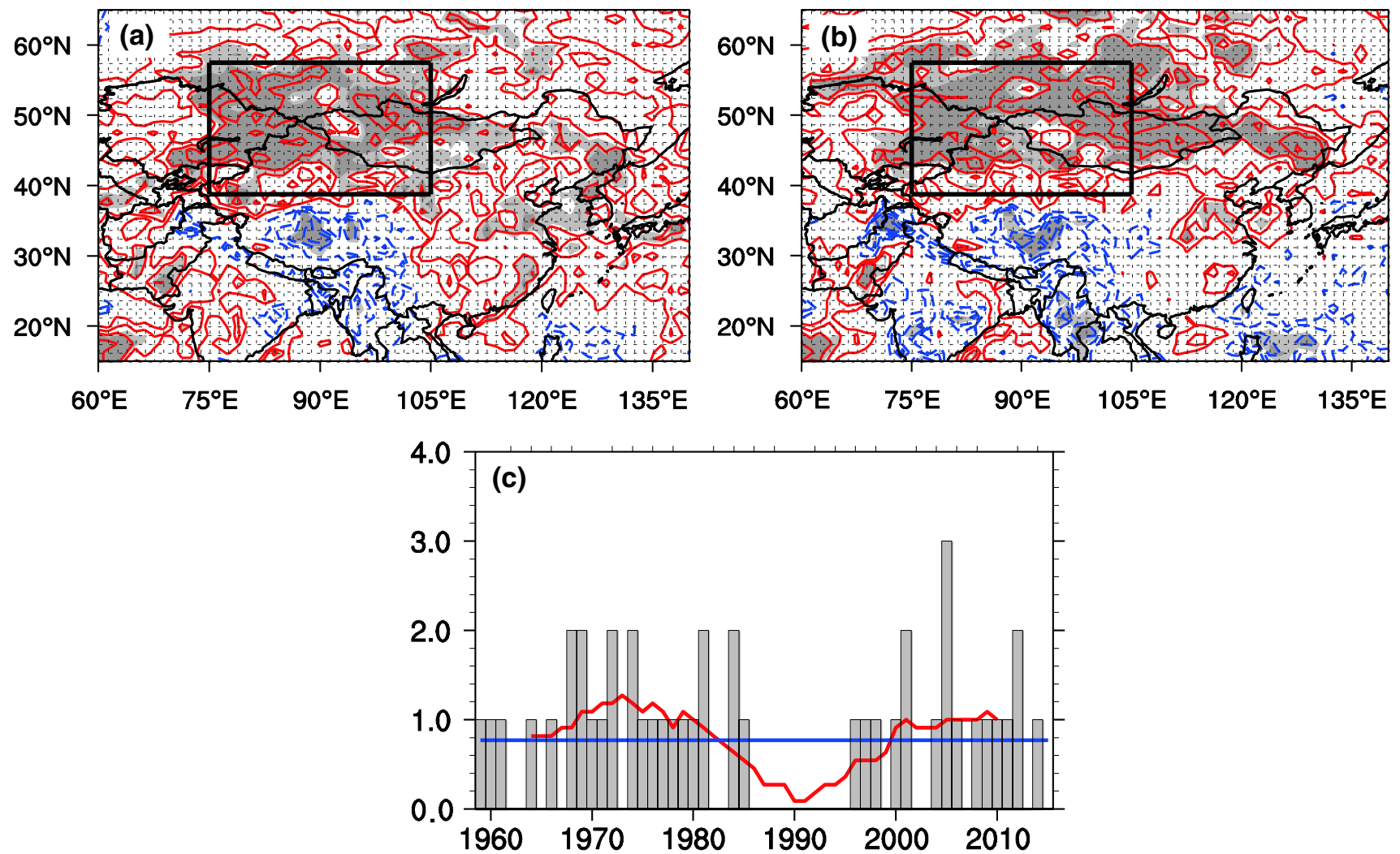

Fig. 3 a Frequency differences of PCEs between active and inactive periods. $\mathbf{b}$ As in $\mathbf{a}$, but between the reactive and inactive periods. The contour interval is 0.2 . The solid red lines and dashed blue lines represent positive and negative anomalies, respectively. Zero lines are omitted. Light and heavy shading denotes the significance at the 0.1 and 0.05 confidence levels, respectively. The black rectangles in a

regional PCEs over the BB region exceeds (falls below) the 57-year average during the active and reactive (inactive) periods (Fig. 3c). The 11-year running mean frequency is lowest in 1990 and increases quickly until 2001, after which it varies very little (approximately 1.0 per winter), which is highly consistent with the warming trend from 1990 to 2013 over the BB region (Cohen et al. 2014). This warming trend might be related to the decrease in Arctic sea ice and the associated increase in the frequency of the Ural blocking high (Mori et al. 2014).

\subsection{Typical circulation features}

It is necessary to show typical circulation features for the regional PCEs over the BB region before discussing circulation characteristics during interdecadal changes. Figure 4 shows the composite results for the 45 regional PCEs. Hereafter, day 0 represents the peak day composite for every event, while days $-\mathrm{N}$ and $\mathrm{N}$ refer to the composite $\mathrm{N}$ days before and after the peak day, respectively. and $\mathbf{b}$ mark the key area $\left(38.75^{\circ} \mathrm{N}-57.5^{\circ} \mathrm{N}, 75^{\circ} \mathrm{E}-105^{\circ} \mathrm{E}\right)$ with notable long-term variations, which is the focus of this study. $\mathbf{c}$ The frequency of PCEs based on area-averaged SAT anomalies over central Asia, which are represented by the rectangles in $\mathbf{a}$ and $\mathbf{b}$. The red line represents the 11-year running average, and the blue line represents the 57-year average

At day -6 , significant SAT anomalies occur north of Lake Balkhash, with a maximum amplitude of $-3{ }^{\circ} \mathrm{C}$ (Fig. 4a). Meanwhile, at upper levels, wave-train anomalies form over Eurasian mid- to high latitudes, with anticyclonic anomalies of approximately $140 \mathrm{gpm}$ centred around the Ural Mountains (Fig. 4k). The wave-train anomalies over the Eurasian continent resemble the circulation pattern associated with the Arctic sea ice retreat (Mori et al. 2014). Through the PV inversion, Takaya and Nakamura (2005) found that precursory cold SAT anomalies over the BB region and an upper level ridge over the Ural Mountains can enhance each other, which contributes to the amplification of the Siberian High. Due to such vertical coupling (Takaya and Nakamura 2005), positive SLP anomalies are gradually enhanced before day -3 (Fig. 4f, g), implying the northward expansion and enhancement of the Siberian High, and the anticyclonic height anomalies at $300 \mathrm{hPa}$ are also enhanced, with a maximum amplitude of $180 \mathrm{gpm}$ (Fig. 4l). Consequently, the SAT anomalies expand eastward, which causes their central amplitudes to increase to $-5^{\circ} \mathrm{C}$ (Fig. 4b). At 


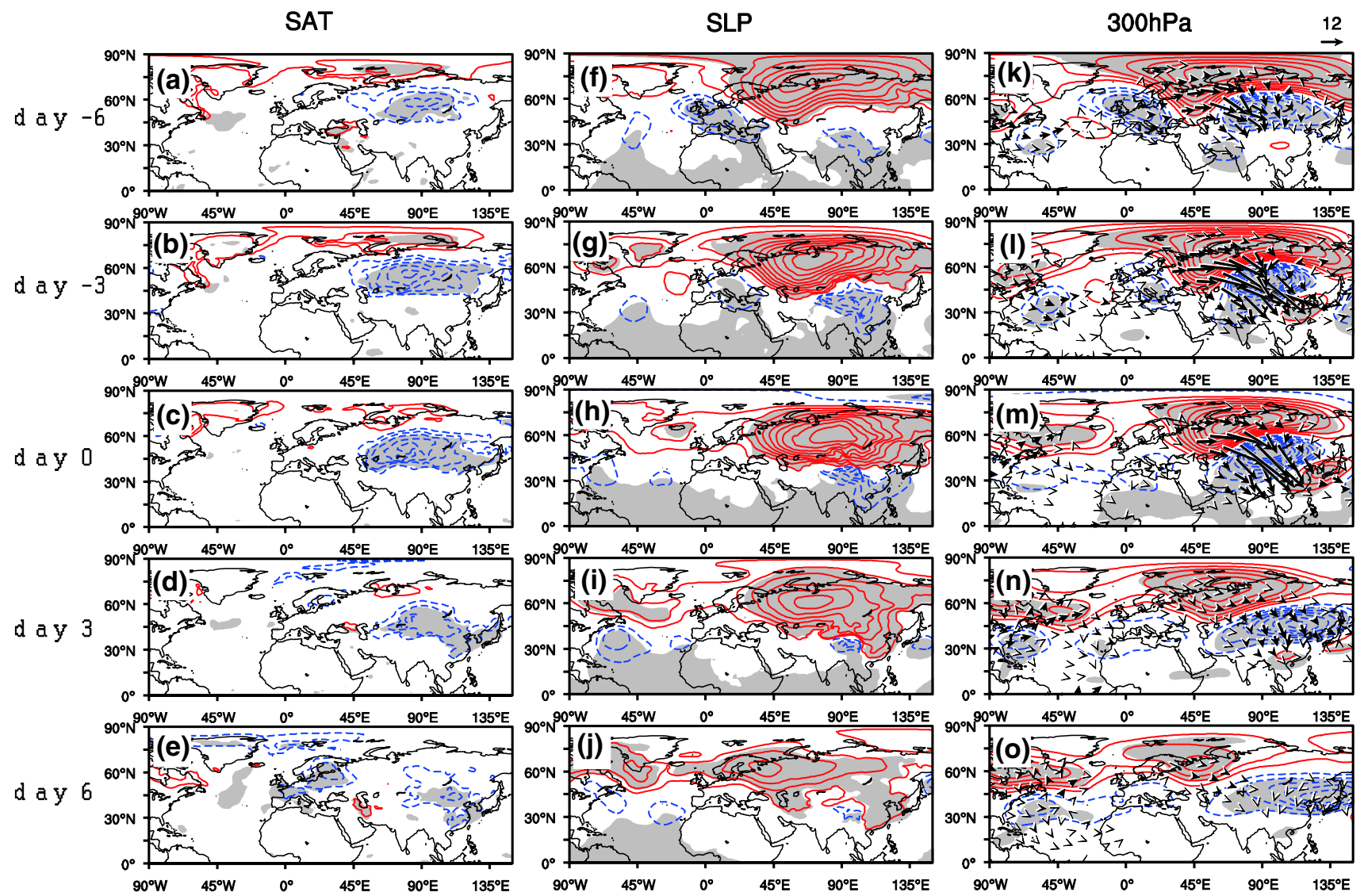

Fig. 4 Composite evolutions of 45 regional PCEs over the Lake Balkhash to Lake Baikal (BB) region, which are identified during the 57 winters. The columns from the left to right represent the SAT anomalies, SLP anomalies and geopotential height anomalies at $300 \mathrm{hPa}$, respectively. The rows from top to bottom represent the results at days $-6,-3,0,3$ and 6 , respectively. The contour intervals in the columns from left to right are $1{ }^{\circ} \mathrm{C}, 2 \mathrm{hPa}$ and 2 dagpm, respectively. Solid red lines and dashed blue lines indicate positive and negative anomalies, respectively. Zero contours are omitted. Shading denotes significant regions at the 0.05 confidence level. The arrows $\left(\mathrm{m}^{2} / \mathrm{s}^{2}\right)$ in the right column represent the wave activity flux day 0, negative SAT anomalies cover the region from the Caspian Sea to northeastern China (Fig. 4c).

In addition to the interaction with SAT anomalies over the $\mathrm{BB}$ region, the persistent anticyclonic anomalies over the Ural Mountains in the upper troposphere are also related with Rossby wave energy dispersion. At day - 6 (Fig. 4k), the wave packets emanate from anticyclonic height anomalies over North America and propagate southeastward, which contributes to the formation of significant cyclonic height anomalies over the North Atlantic. Then, height anomalies over the North Atlantic and Eurasian mid- to high latitudes are connected through the propagation of Rossby wave packets. Consistent with the upstream energy supply at day 0 (Fig. $4 \mathrm{~m}$ ), anticyclonic height anomalies over the Ural Mountains achieve their maximum amplitudes, while the upstream circulation gradually disappears, especially over Europe and the North Atlantic. Note that both the positive height anomalies over the Ural Mountains and East Asia and the negative height anomalies over the $\mathrm{BB}$ region extend in the northeast-southwest direction, which is consistent with the southeastward propagation of Rossby waves over Asia. This tilted structure is regarded as an important explanation for extensive and persistent cold events in China (Bueh et al. 2011a, b).

After day 0, significant positive SLP anomalies propagate southeastward over southern China (Fig. 4i, j). The SAT anomalies over the BB region extend southeastward accordingly and decrease gradually (Fig. 4d, e). In the upper troposphere (Fig. 4n, o), positive height anomalies remain near the Ural Mountains but retreat westward, and the amplitude decreases quickly. The negative height anomalies, which originally resided over the BB region, gradually propagate southward and dominate the positive height anomalies over East Asia.

Therefore, due to Rossby wave propagation, regional PCEs over the BB region are characterized by wave-train height anomalies from North America to the Eurasian continent, with the most notable positive and negative height 
anomalies occurring over the Ural Mountains and the BB region, respectively, in the upper troposphere. In addition, the formation of positive height anomalies over the Ural Mountains may also be attributable to the interaction with negative SAT anomalies that formed approximately 1 week before the peak day.

\subsection{Interdecadal changes in background circulation}

It is natural to question the role of background circulation in the modulation of regional PCE frequency over the BB region. Background circulation features are obtained by averaging the meteorological fields over the three periods individually. Figure 5 shows the circulation differences between the first active period and the inactive period. As in Fig. 3, the inactive period is regarded as the reference period. Evidently, wave-train-like anomalies formed over mid- to high latitudes from North America to Eurasia (Fig. 5a). The Ural Mountains are dominated by positive height anomalies, which are surrounded by two negative height anomaly centres over western Europe and East Asia. In addition, a negative height anomaly resides over the northeastern region of North America, and it extends eastward and connects with the negative height anomaly over western Europe, while positive height anomalies are centred over Greenland. Thus, interdecadal changes in the geopotential height field in the upper troposphere during the active period are in phase with typical circulation features (as revealed in Sect. 3.2), especially for those over Eurasia. In other words, the interdecadal changes in the active period are favourable for the occurrence of regional PCEs over the

(a) $300 \mathrm{hPa}$



(c) SAT

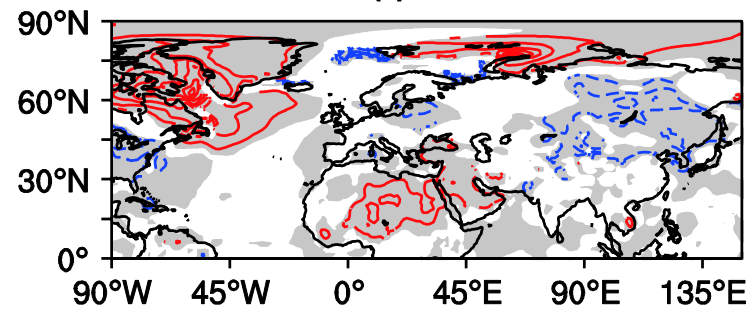

Fig. 5 Differences in background circulations between the active period (1959-1984) and the inactive period (1985-1999). a Geopotential height (dagpm); b SLP $(\mathrm{hPa})$; $\mathbf{c}$ SAT $\left({ }^{\circ} \mathrm{C}\right)$; and d height tendency ( $\mathrm{m} /$ day) forced by the convergence of transient vorticity fluxes.
BB region. Positive SLP anomalies over the mid- to high latitudes of Eurasia (Fig. 5b) are beneficial for the northwestward expansion of the Siberian High, which is helpful for the southward intrusion of cold air from higher latitudes.

SATs show a negative anomaly near the BB region (Fig. 5c). According to Takaya and Nakamura (2005), negative SAT anomalies may contribute to the formation and persistence of positive height anomalies over the Ural Mountains. Therefore, interdecadal changes in the SAT field are also favourable for the occurrence of regional PCEs over the $\mathrm{BB}$ region during the active period.

Figure $5 \mathrm{~d}$ shows the changes in transient eddy feedback forcing. The baroclinic influence is marginal in the upper troposphere; therefore, only the barotropic influence is shown (Fig. 5d). Due to the counteraction between the baroclinic influence and the barotropic influence, the amplitude of the barotropic influence (Fig. 5d) is regarded as the upper limit of transient eddy feedback forcing. Evidently, transient eddy feedback forces negative height tendencies over northwestern North America to the North Atlantic and western Europe and positive height tendencies over the Ural Mountains and Greenland. Positive height anomalies $(30 \mathrm{~m})$ over the Ural Mountains can develop within 1.5 days due to transient eddy feedback forcing with an amplitude of $20 \mathrm{~m} /$ day. Likewise, negative height anomalies $(-40 \mathrm{~m})$ over western Europe can develop within 1 day due to transient eddy feedback forcing with an amplitude of $50 \mathrm{~m} /$ day. Therefore, transient eddy feedback forces interdecadal circulation variations to a great extent, which facilitates the formation of typical circulation patterns, especially over western Europe and the Ural Mountains.

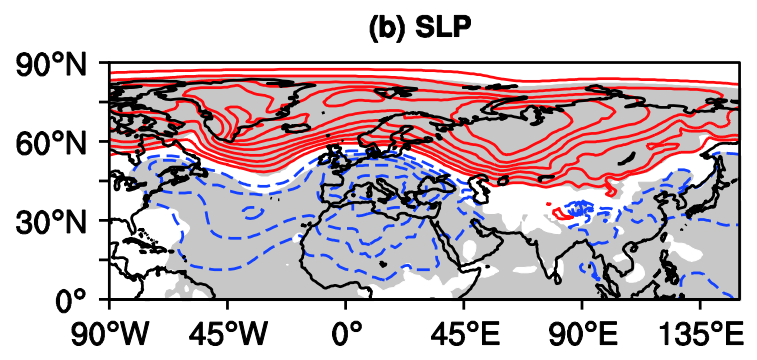

(d) DZDT300hPa

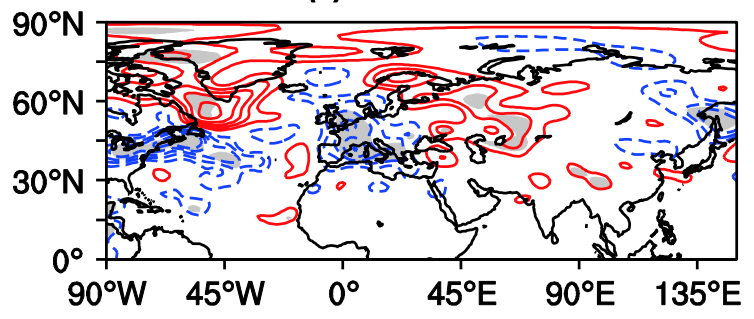

Contour intervals in a-d are 1 dagpm, $0.5 \mathrm{hPa}, 0.5^{\circ} \mathrm{C}$ and $10 \mathrm{~m} /$ day, respectively. Zero contours are omitted in all panels. Only contours over the significant region are drawn in c. Solid red lines and dashed blue lines indicate positive and negative anomalies, respectively 
The differences between the recent reactive period and the inactive period are illustrated in Fig. 6. Generally, the differences are similar to those in Fig. 5 but with stronger amplitudes. Specifically, the negative height anomaly amplitudes over the western Europe and the positive height anomaly amplitudes over the Ural Mountains increase to approximately -50 and $50 \mathrm{gpm}$, respectively (Fig. 6a). In contrast, the centre of negative height anomalies over East Asia moves westward to Lake Baikal, and the associated area of the anomalies shrinks. The positive SLP anomaly amplitude centred over the Ural Mountains is approximately $5 \mathrm{hPa}$ (Fig. 6b). Consequently, negative SAT anomalies prevail over the BB region (Fig. 6c). Therefore, compared with the inactive period, the background circulation in the recent reactive period also changes in a way that facilitates the formation of typical PCE circulation patterns over the BB region.

Transient eddy feedback forcing also contributes to the negative height tendency anomalies over the northeastern United States and western Europe (Fig. 6d), producing changes that resemble the circulation changes during the last two periods (Fig. 5d). In contrast, over Asia, transient eddies do not force positive height tendency anomalies over the Ural Mountains like they do in the first active period. Instead, they induce negative height tendency anomalies over East Asia, with a maximum amplitude of $-40 \mathrm{gpm} /$ day, which contribute substantially to the persistence of negative height anomalies (approximately $-30 \mathrm{~m}$ ) over East Asia. In fact, both of the active periods are characterized by weakened transient eddy activity (as measured by the high-frequency meridional momentum flux $u^{\prime} v^{\prime}$ at $250 \mathrm{hPa}$ ) over the Eurasian continent (not shown). Thus, it is inferred that the transient eddy vorticity flux

(a) $300 \mathrm{hPa}$

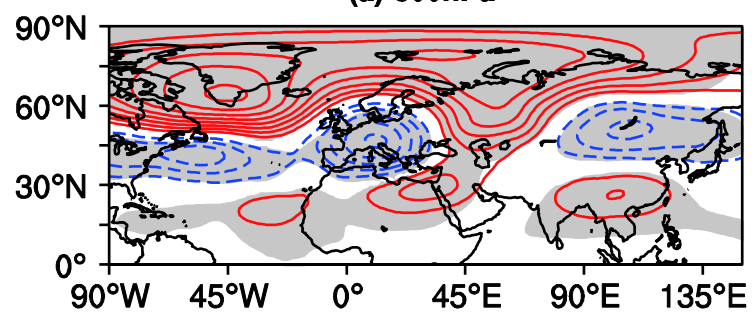

(c) SAT

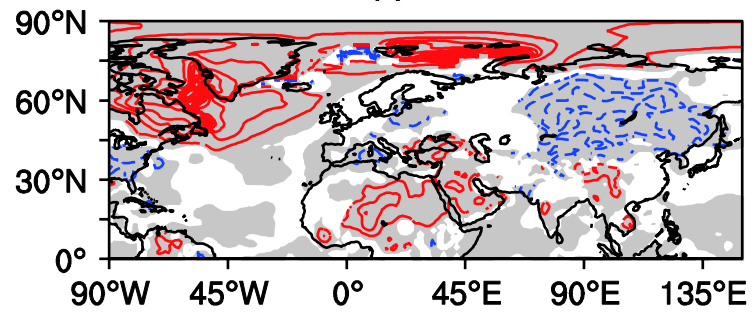

may vary during the two active periods, which deserves additional research.

Therefore, during the active period, geopotential height tends to increase over the Ural Mountains and decrease over western Europe and East Asia. In addition, transient eddy feedback forcing plays an important role in producing this type of circulation pattern.

\section{Conclusions and discussion}

This study identifies PCEs at every grid point over Asia using the JRA-55 daily reanalysis dataset. After removing the long-term linear trend from the daily meteorological fields, the results show that the BB region experienced a significant interdecadal variation in the PCE frequency during the past 57 winters. Thus, regional PCEs over the BB region are the focus of this study. From 1985 to 1999, the regional PCEs over the BB region occurred with a lower frequency compared with those occurring before and after. These three periods are referred to as the active period, the inactive period and the reactive period. Based on the composite analysis, the regional PCEs are characterized by wave-train anomalies in the upper troposphere from the North Atlantic to Eurasia. Positive height anomalies persist over the Ural Mountains, and negative anomalies persist over western Europe and the BB region. Positive SLP anomalies over Eurasia indicate the northward expansion of the Siberian High, which corresponds to the persistent cold anomalies over the BB region.

Our study reveals that changes in the background circulation can modulate the frequency of regional PCEs over the $\mathrm{BB}$ region. By comparing circulation patterns between the 
two active periods and the inactive period, the wave-trainlike anomalies in the two active periods are found to facilitate the formation of typical circulation patterns, especially over the Eurasian continent. The wave-train-like anomalies at the interdecadal timescale agree well with the typical circulation of regional PCEs over the BB region at the subseasonal timescale. Thus, interdecadal variations in the background circulation evidently modulate the occurrence of PCEs over the BB region. Transient eddy feedback forcing exerts positive influences on the formation of wave-trainlike anomalies at the interdecadal timescale over Eurasia by exerting negative height anomaly tendencies over western Europe during the two active periods, positive anomalies over the Ural Mountains during the earlier active period, and negative anomalies over East Asia during the recent reactive period.

The NCEP/NCAR reanalysis data (Kalnay et al. 1996) with a horizontal resolution of $2.5^{\circ}$ in both latitude and longitude was also used to the check the robustness of the above results during the same period from 1959 to 2015 . Figure 7 shows the frequency differences for PCEs between the active periods and the inactive period. In this figure, positive anomalies occur over the BB region and East Asia, and negative ones occur over the Tibetan Plateau, which resembles Fig. 3 quite well but with a coarser resolution. However, the significant positive anomalies over East Asia are stronger and more extensive than those in Fig. 3. The circulation features in the regional PCEs over the BB region at the interdecadal time scale (not shown) are almost the same as those revealed by the JRA-55 reanalysis data. Therefore, our results are not sensitive to the reanalysis dataset used, at least for the $\mathrm{BB}$ region.

If the linear trend is not removed from the meteorological fields, grid-based PCEs over Asian mid-latitudes (especially for the central part of China along $40^{\circ} \mathrm{N}$ ) show a substantial decreasing trend over the 57-year period (not shown) rather than an interdecadal variation. This decreasing trend is mainly attributable to warming SATs (Fig. 1), which decrease the amplitudes of the cold air masses.

Screen (2014) stated that Arctic amplification can lead to faster warming rates on cold days than on warm days through the meridional advection effect, which further reduces the variance in the zonal-mean subseasonal temperature variance in northern mid- to high latitudes. Based on this observation, Fig. 8 shows the subseasonal variability in SATs over the BB region. Clearly, the 11-year running mean variability over the BB region is enhanced after 2000 , which is different from the decreasing trend in the zonal mean (Screen 2014). Note that the variability shows a similar interdecadal variation to that of regional PCEs over the $\mathrm{BB}$ region, but the relationship between them under global warming or Arctic amplification is unclear.

In addition to the important role of sea ice loss in causing wave-train anomalies (Liu et al. 2012a, b; Mori et al. 2014), as discussed in Sect. 3, SST anomalies may also have

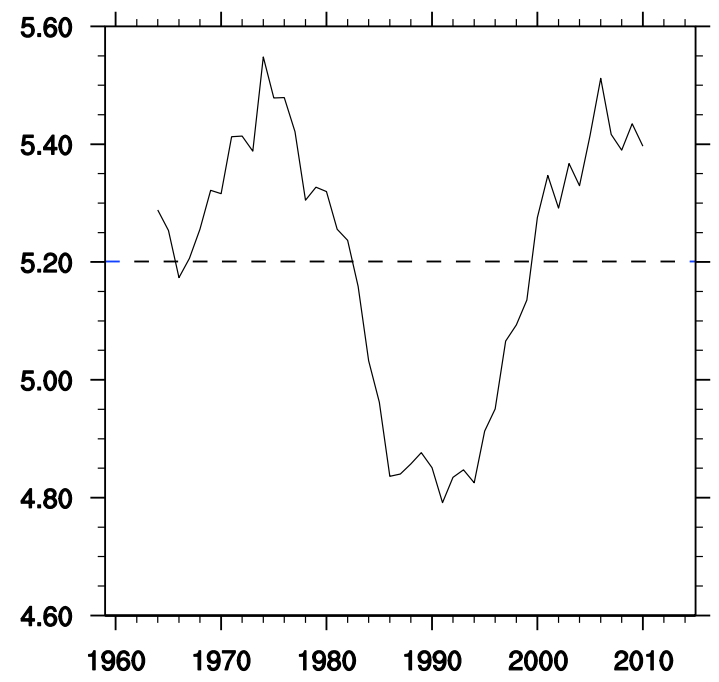

Fig. 8 The 11-year running mean of subseasonal SAT variability $\left({ }^{\circ} \mathrm{C}\right)$ over the BB region. The dashed line indicates the 57 -year mean value
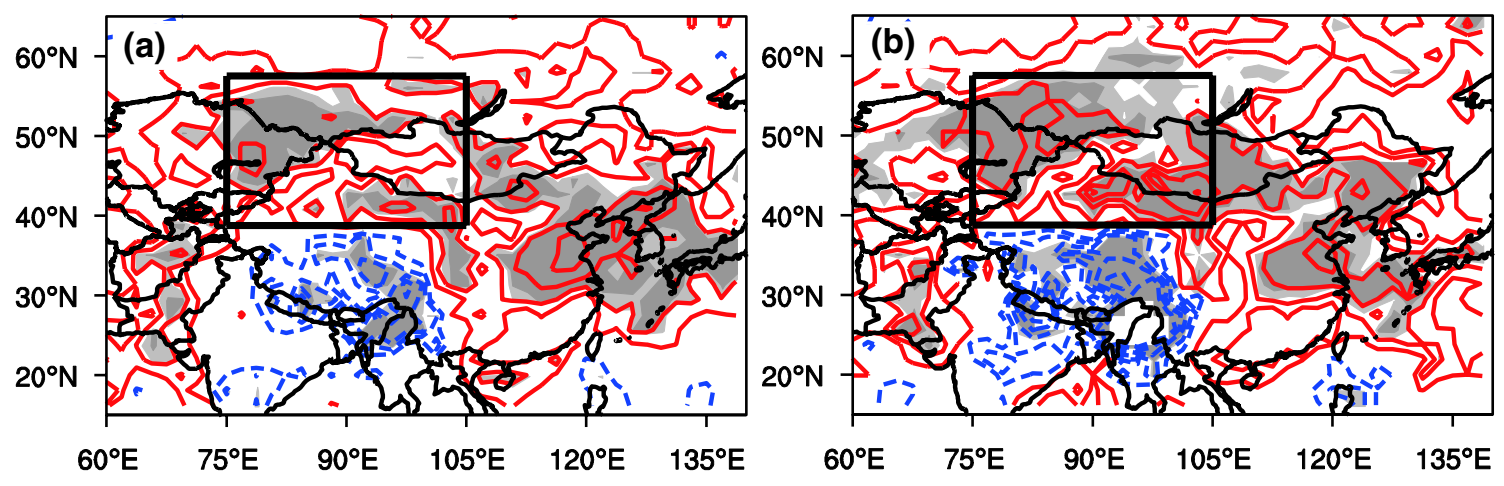

Fig. 7 Same as in Fig. 3a, b, but by using the NCEP/NCAR reanalysis data 
an important influence. Li et al. (2006) found that positive SST anomalies over the northwestern Atlantic are beneficial for wave-train anomalies in autumn and early winter from the Atlantic Ocean to the Eurasian continent in the upper troposphere. In addition, Liu et al. (2012a, b) showed that in winter, the west (warm) and east (cold) SST anomaly patterns over the northwestern Atlantic are also beneficial for wave-train anomalies across the Eurasian continent. Wave trains revealed by the above two studies are similar to those in Figs. 5a and 6a, except for the negative height anomalies over East Asia. In fact, SST differences between the active period and inactive period show positive anomalies over the northwestern Atlantic (not shown), indicating that interdecadal SST variation may play a positive role in producing wave-train-like anomalies over the Eurasian continent, especially for negative (positive) anomalies over western Europe (the Ural Mountains). As stated in Sect. 3.3, positive height anomalies over the Ural Mountains (Fig. 5a) are modulated by transient eddy feedback forcing (Fig. 5d). Therefore, the influence of SST anomalies over the Atlantic on circulation over the Eurasian continent deserves additional research.

As one of the largest components in the global climate system, the East Asian winter monsoon also exhibits significant long-term variations, with a weak period after the mid-1980s (Nakamura et al. 2002; Jhun and Lee 2004; Wang and Fan 2013; Wang and Chen 2014). Recent studies have revealed that the weakened East Asian winter monsoon strengthened after the mid-2000s, leading to the stagnation of the SAT warming trend over China (Liang et al. 2014) and East Asia (Wang and Chen 2014). The interdecadal variation in the East Asia winter monsoon appears to coincide with that of regional PCEs over the BB region, which also deserves additional research in the near future.

Acknowledgements This work is supported jointly by the National Key R\&D Program of China (Grant no. 2016YFA0600702), the National Basic Research Program of China (2015CB953904), the Chinese Natural Science Foundation (41575057), Major Projects of Natural Science Research in Universities of Jiangsu (15KJA170004) and the Priority Academic Program Development of Jiangsu Higher Education Institutions (PAPD). The NCAR Command Language (NCL) was used for the calculations and for drawing the plots.

Open Access This article is distributed under the terms of the Creative Commons Attribution 4.0 International License (http://creativeco mmons.org/licenses/by/4.0/), which permits unrestricted use, distribution, and reproduction in any medium, provided you give appropriate credit to the original author(s) and the source, provide a link to the Creative Commons license, and indicate if changes were made.

\section{References}

Barnes EA (2013) Revisiting the evidence linking Arctic amplification to extreme weather in midlatitudes. Geophys Res Lett 40:4734-4739

Bueh C, Shi N, Xie Z (2011a) Large-scale circulation anomalies associated with persistent low temperature over Southern China in January 2008. Atmos Sci Lett 12:273-280

Bueh C, Fu X, Xie Z (2011b) Large-scale circulation features typical of wintertime extensive and persistent low temperature events in China. Atmos Ocean Sci Lett 4:235-241

Chen H, Sun J (2015) Changes in climate extreme events in China associated with warming. Int J Climatol 35:2735-2751

Cohen J, Screen JA, Furtado JC, Barlow M, Whittleston D, Coumou D, Francis J, Dethloff K, Entekhabi D, Overland J, Jones J (2014) Recent Arctic amplification and extreme mid-latitude weather. Nat Geosci 7:627-637

Duchon CE (1979) Lanczos filtering in one and two dimensions. J Appl Meteorol 18:1016-1022

Francis J, Vavrus SJ (2012) Evidence linking Arctic amplification with changing weather patterns in mid-latitudes. Geophys Res Lett 39:L06801

Han Z, Li S, Liu J, Gao Y, Zhao P (2016) Linear additive impacts of Arctic sea ice reduction and La Niña on the northern hemisphere winter climate. J Clim 29:5513-5532

Holopainen E, Fortelius C (1987) High-frequency transient eddies and blocking. J Atmos Sci 44:1632-1645

IPCC (2013) Climate change 2013: the physical science basis. Contribution of Working Group I to the Fifth Assessment Report of the Intergovernmental Panel on Climate Change. Cambridge University Press, Cambridge, United Kingdom and New York, NY, USA, pp 1535

Jhun JG, Lee EJ (2004) A new East Asian winter monsoon index and associated characteristics of the winter monsoon. J Clim 17:711-726

Kalnay E, Kanamitsu M, Kistler R, Collins W, Deaven D, Gandin L, Iredell M, Saha S, White G, Woollen J, Zhu Y, Chelliah M, Ebisuzaki W, Higgins W, Janowiak J, Mo KC, Ropelewski C, Wang J, Leetmaa A, Reynolds R, Jenne R, Joseph D (1996) The NCEP/NCAR 40-year reanalysis project. Bull Amer Meteor Soc 77:437-470

Kobayashi S, Ota Y, Harada Y, Ebita A, Moriya M, Onoda H, Onogi K, Kamahori H, Kobayashi C, Endo H, Miyaoka K, Takahashi K (2015) The JRA-55 reanalysis: general specifications and basic characteristics. J Meteorol Soc Jpn Ser II 93:5-48

Lau N-C, Holopainen EO (1984) Transient eddy forcing of the timemean flow as identified by geopotential tendencies. J Atmos Sci 41:313-328

Li S, Hoerling MP, Peng S, Weickmann KM (2006) The annular response to tropical Pacific SST forcing. J Clim 19:1802-1819

Liang S, Ding Y, Zhao N, Sun Y (2014) Analysis of the interdecadal changes of the wintertime surface air temperature over mainland China and regional atmospheric circulation characteristics during 1960-2013. Chin J Atmos Sci (in Chinese) 38:974-992

Liu G, Ji L, Wu R (2012a) An east-west SST anomaly pattern in the midlatitude North Atlantic Ocean associated with winter precipitation variability over eastern China. J Geophys Res Atmos 117:D15104

Liu J, Curry JA, Wang H, Song M, Horton RM (2012b) Impact of declining Arctic sea ice on winter snowfall. Proc Natl Acad Sci USA 109:4074-4079

Mori M, Watanabe M, Shiogama H, Inoue J, Kimoto M (2014) Robust Arctic sea-ice influence on the frequent Eurasian cold winters in past decades. Nat Geosci 7:869-873 
Nakamura H, Izumi T, Sampe T (2002) Interannual and decadal modulations recently observed in the Pacific storm track activity and East Asian winter monsoon. J Clim 15:1855-1874

Palmer T (2014) Atmospheric science. Record-breaking winters and global climate change. Science 344:803-804

Peng J, Bueh C (2011) The definition and classification of extensive and persistent extreme cold events in China. Atmos Ocean Sci Lett 4:281-286

Screen JA (2014) Arctic amplification decreases temperature variance in northern mid- to high-latitudes. Nat Clim Change 4:577-582

Screen JA, Simmonds I (2010) The central role of diminishing sea ice in recent Arctic temperature amplification. Nature 464:1334-1337

Screen JA, Simmonds I (2013) Exploring links between Arctic amplification and mid-latitude weather. Geophys Res Lett 40:959-964

Screen JA, Deser C, Simmonds I (2012) Local and remote controls on observed Arctic warming. Geophys Res Lett 39:L10709

Serreze MC, Barrett AP, Stroeve JC, Kindig DN, Holland MM (2009) The emergence of surface-based Arctic amplification. Cryosphere 3:11-19

Takaya K, Nakamura H (2001) A formulation of a phase-Independent wave-activity flux for stationary and migratory quasigeostrophic eddies on a zonally varying basic flow. J Atmos Sci 58:608-627
Takaya K, Nakamura H (2005) Mechanisms of intraseasonal amplification of the cold Siberian high. J Atmos Sci 62:4423-4440

Tao S, Wei J (2008) Severe snow and freezing-rain in January 2008 in the southern China. Clim Environ Res (in Chinese) 13:337-350

Wallace JM, Held IM, Thompson DWJ, Trenberth KE, Walsh JE (2014) Global warming and winter weather. Science 343:729

Wang L, Chen W (2014) The East Asian winter monsoon: re-amplification in the mid-2000s. Chin Sci Bull 59:430-436

Wang H, Fan K (2013) Recent changes in the East Asian monsoon. Chin J Atmos Sci (in Chinese) 37:313-318

Wen M, Yang S, Kumar A, Zhang P (2009) An analysis of the largescale climate anomalies associated with the snowstorms affecting China in January 2008. Mon Weather Rev 137:1111-1131

Zhou W, Chan JCL, Chen W, Ling J, Pinto JG, Shao Y (2009) Synoptic-scale controls of persistent low temperature and icy weather over Southern China in January 2008. Mon Weather Rev 137:3978-3991 